\title{
Effort and Collective Creation: Experience in Air Traffic Control Work
}

\author{
Alice $\operatorname{Itani}^{1}$ \\ ${ }^{1}$ Universidade Estadual Paulista Unesp, São Paulo, Brazil \\ Correspondence: Alice Itani, Av. Higienopolis, 195 São Paulo 01238-001, Brazil.
}

Received: July 7, 2015

Accepted: July 20, 2015

Available online: August 5, 2015

doi:10.11114/ijsss.v3i5.1007

URL: http://dx.doi.org/10.11114/ijsss.v3i5.1007

\begin{abstract}
How can work also represent a perspective of creation? We start from the hypothesis that air traffic controllers make an effort to cope with very hard work and to develop improvement processes when carrying out the activity, which can be considered creation. Our objective is to analyze the working conditions of air traffic controllers starting from the experience of the controller. There is effort, which is above all both cognitive and physical, of an activity developed with mental representations that cannot always be analyzed by simple observation. This is a reflection based on studies carried out with air traffic controllers since 1997 in São Paulo and Rio de Janeiro.
\end{abstract}

Keywords: air traffic controller; São Paulo; Rio de Janeiro; aviation; cognitive effort; collective creation.

\section{Introduction}

Can work provide the conditions necessary for creation? Despite the type of organization to which the worker is subordinated, what meaning can work assume? These are the questions we seek to discuss in this text.

Despite the types of organization with their rules and established structures, in which production processes are found, the production process as established by the rules has been unable to cope with the failings and uncertainties of systems, or with the unforeseen circumstances that occur on a daily basis and that involve the incoherencies of the forms of organization and their management policies. No organization could function without the organization of workers, regardless of the management and its rules. On the other hand, it cannot be said that organizations are in total control of the work groups.

It is a fact that workers included in a production process do not dominate the whole process and are subject to the rules of the organization and the systems established for controlling them. However, they are not reduced to a simple machine. The act of the worker is not reduced to mechanical acts since there is intention and action, as argued by Castoriadis (1950 and 1974). The presence of rational systems in production processes does not mean that there is only a duality of domination and servitude, as analyzed by Castoriadis (1950/1974) and Habermas (1973). Even in more rigid systems, worker action is a conscious act and they are not reduced to being simple executors. As social and historical beings, individuals think, mobilize their acts to cope with their functions and know what they do and how they do it. However, they do not always manage to apprehend the relationships that are established in production processes.

The challenge of seeking to understand some facets of the relationships that are established in the daily life of workers can be undertaken by way of an activity that does not allow for mistakes when it is being carried out and that has a strong impact on the safety of people. Some of the activities in commercial civil aviation, as is the case with piloting and air traffic control, are included in such cases. Studies carried out by Moreira \& Vidal (1999) and Motter (2006) in air traffic control centers in Brazil showed the extent of the work load and the complexity of the activity. Nevertheless, reflection about the dimension of work, considering it to be part of creation, also deserves to be the object of study. This work is realized with effort and the effectiveness of the control depends much more on collective creation.

\section{Objective and Method}

The objective of this paper is to reflect on data from a study that has been carried out since 1997 with air traffic controllers. The hypothesis is that air traffic controllers make an effort to cope with the density of their work and develop strategies for improving the process of carrying out the activity, which can be considered akin to creation. Effort is understood to be the action of the worker in carrying out the activity that involves the conscious intention and action of mobilizing their capacity for work, and for carrying out these activities with the aim of achieving a specific purpose. Creation is understood to mean what the worker does as a result of their knowledge and experiences to make 
their activity more effective. It involves a conscious action for improving the process of carrying out the activity attributed to them, which alters what is established. This creation is analyzed by way of three items: the development of new strategies for improving the process for carrying out the work; sharing experiences; and the organization of a common language, which is effective and legitimate.

The experience, as it is experienced, is a way of understanding the facets of the work condition. The perspective of Gianini (2013) can be used because it comprises experience that is not just personal; it is collective - it incorporate other experiences individuals communicate the fact that they are suffering from the same situation. There is a constant interchange of voices and expressions, of a common feeling, transforming small everyday stories into an experience, a way of understanding that is also common and collective. That is why the experience may be apprehended within its own territory, which is the territory of daily life, where it becomes possible. A singular social condition is intertwined with that of the worker within a daily spatial structure, which is the workspace. In this sense, in the way in which workers express themselves, their words are not passive. It also raises the possibility for reflection on their identity situation, between what they are doing and what their prospects are. The experience is constructed during the habitual cycles and the identity situation depends on this order, on a space-time continuity as a symbol of human singularity (Gianini, 2013). It is also the result of accumulated knowledge resulting from learning processes, because of the references created, with their own meanings. So when they express themselves in their statements, they also reveal an experience that is common, with its own meaning.

This experience is analyzed by way of six items: how an activity, such as the one air traffic controllers do, is carried out; to what extent air traffic controllers dominate the process, from the perspective of what they do; their understanding of the work process, by how they explain each of their activities; their knowledge for undertaking the activity seen in terms of their daily acts and the speed with which they respond to complex situations; the responsibility with which they respond to the activities, and their learning capacity for incorporating new situations.

The study of the work of air traffic controllers, which has been developed since 1997, involved an investigation of the documents relating to the existing rules and standards of this activity. The work process was monitored as it is developed by the controllers, based on long periods of observation in air traffic control rooms in São Paulo and Rio de Janeiro and notes that were taken about the way in which each controller understands and explains the work they do. Observation took six months and took part on different days of the week and at different times, as well as at different periods in the year, accompanying teams on all three shifts. Statements were also taken from the controllers while they were working and also outside the workplace. During the study period this work involved 141 controllers in São Paulo and 89 in Rio de Janeiro. Some 10\% of the controllers in São Paulo were civilians and $90 \%$ came from a military background; six were women. In Rio de Janeiro, around $20 \%$ of the controllers are civilians and $80 \%$ had a military career.

\section{Air Traffic Control Work}

The work of air traffic control consists in ensuring that flights move safely in air space. There is a series of activities for guiding the pilots of flights moving within the airways, notably in areas where movement is more intense. To develop this activity, they rely on communication systems and an operational system for controlling circulation within the air space.

The Brazilian air traffic control system was devised and structured as part of the military defense system and the Aeronautical Command is responsible for managing it. With its function of defining policies for the circulation of traffic in Brazilian air space this organ also has a public air traffic safety and control function. Sisdacta (Integrated Air Defense and Air Traffic Control System) was introduced in the 1970s and has been updated over the last twenty years. The control system includes the circulation routes in air space, control of the approaches in cities with the greatest amount of traffic and traffic control at the airports. To control the air space in a territory covering the 22 million square kilometers, as well as sea areas, the system is organized by way of a national and regional control centers, spread throughout the main regions in the country. The airport control towers in the main cities are linked into these regional centers.

The air transport industry has been growing constantly and particularly so over the last thirty years. The number of flights doubled in the ten years between 1990 and 2000 and grew by $84 \%$ between 2000 and 2010. The number of passengers almost tripled in ten years between 2003 and 2012. From 2009 to 2010 growth was 24\%. In 2012, more than 107 million passengers were carried, most of them on domestic flights, with around 83\% of the total (ANAC, 2013). Air traffic control monitored more than one million flights that circulated around the country (ANAC, 2013). Most of the passengers fly into or out of airports in the southeast of the country, with around 43\% of the total in 2012 spread between the airports of Rio de Janeiro and São Paulo, notably because of the policy of centralizing flights leaving from these airports. The shuttle service between Rio de Janeiro and São Paulo leads this movement, with around seven million passengers in 2012 (ANAC, 2013); these are the biggest air traffic control centers in the country.

The airport infrastructure, however, is not growing at the same pace as air traffic and the numbers of air traffic control 
staff have not accompanied the increase in traffic or the number of passengers. Some changes have been carried out over the last ten years in airport management, particularly with the privatization of airport services.

\section{Work Content and Effort}

In order to understand the work of air traffic controllers we need initially to check the context in which this function is situated, which is the world of aviation, with the changes that have been occurring over the last thirty years and on three levels. The first level is the increase in the number of flights. The second is the increase in the number of passengers and the number of passengers per flight; each flight carries as many as 400 passengers, as is the case with Boeing equipment. This increase in the number of passengers on each flight brings consequences for the air traffic controller to the extent that this translates into an increase in responsibility for the safety of the passengers. The same applies with regard to the pilots. To these two changes has to be added the increase in the speed of the systems and equipment, which altered the world of aviation, notably over the last three decades with the spread of jet aircraft.

How is this experienced by the air traffic controller?

\subsection{Organization of the work}

Traffic control in the control room is organized in sectors. Each of the sectors is responsible for an area of the region to be controlled and for the type of control. In the case of flights that are visually controlled, like helicopters and small jets, for example, which fly at low speeds, they are organized in one sector. The other sectors control large jets on commercial flights. Each sector is coordinated by two controllers, supported by a console and three main monitors. The first monitor shows a map of the air space, on which can be identified a figure 8 shape. Within it is the image of the area, which represents the specific air space under the responsibility of the team. The second monitor shows an image of the region's air space. The third monitor has a screen showing a larger image of the air space under control and the flights moving along the routes. Alongside these monitors is the communication system equipment, like the radio and a telephone.

When entering the control room we see a semicircle with six sectors, side by side. There is a strategically placed central table from which all sectors, which are also known as positions, can be seen. In this central position is a supervisor who is responsible for controlling the traffic of the period. He is also supported by monitors and equipment, the central system of the regional area being controlled and by a communication system.

\subsection{Work Content}

The working day of the controller starts with a briefing, in which the team from the previous shift reports the main happenings of the day and the traffic conditions. Within the flight monitoring activities, the eight most important are as follows:

a) checking the flights that are programmed for the working day using the PH hourly schedule program; these can be seen on one of the monitors. Controllers then have to check the flights that appear on their monitor screen and that are represented by icons: numbers and letters;

b) decodifying or deciphering the symbols, by distinguishing the colors and numbers with the corresponding letters;

c) analyzing the route possibilities existing in the sector's space, by assessing them in relation to other flights en route;

d) deciding on the route to be allocated, ensuring that there is no other flight planned for the route at that time and ensuring there is a minimum horizontal distance or nine kilometers between flights. In emergency situations some strategies may be put into practice. One of them is stacking flights, one above the other, at a distance of between 300 and 800 meters, according to the type of equipment;

e) identifying the pilot and his demand by the radio and then confirming the flight details and checking that they are the same as those presented on the screen;

f) recodifying the information using air traffic codes;

g) transmitting the route to the pilot over the radio;

h) inputting the route allocated, once it has been confirmed by the pilot, in order to insert it in the programming sequence. Many of the controllers also undertake a ninth activity, which is to write down the route on a piece of paper, called a strip. This activity, which used to be compulsory, was abandoned with the introduction of new equipment and systems. However, many do not feel secure and retain the activity, since during the observation period it was necessary to use them, above all in case of emergency situations, like a breakdown in the transmission of the data system.

Of all these activities, there are four that demand concentration and attention. They are those corresponding to data identification, interpretation, recodification and due processing. These data appear on the monitor screen as symbols, like numbers and letters and in different colors. This act of seeing is not simply looking at the symbols that appear, but 
also observing the movement and committing it to memory. Some blocks of colors move constantly on the screen, while others do not. In some cases, it is necessary to look for other data that are not on the monitor. For example, certain flights that only pass through the controlled region's airways and that do not land, undergo guidance from the controllers. There is also a need to control flights that may enter the area under their control. As soon as the visualized point on the monitor has been localized, a cursor is used to open a window located in the lower corner of the monitor to open other data. These are data about the route and sequence of flights that will be soon moving.

In these cases the controller mobilizes different levels and functions of the controller's brain system. These data must be identified and understood so that they can be sure of the decisions they take. These identification, analysis and data treatment activities for preparing information require a mental representation and memorization effort, understood by Luria (1973) as being efforts that make demands on the brain system as a whole. This is justified by the fact that the information needed for the control activity is not given a priori. It is prepared by way of image processing - an activity heavily supported by images - or the visual representation of the control system, the icons that appear on the screen and the representation of the air space. Panofsky (1939) and Mitchel (1986) also analyzed that the images do not exist per se, but are constructed as mental representations. They are constructed on a set of other representations that form part of the experience of each one, which is associated with the specific context. That is why these images undergo an identification, interpretation, perception, memory and treatment process. Based on Luria (1973) image processing activities depend on a set of cerebral activities and there is an effort expended, which is understood as being a cognitive effort.

Another aspect of this activity is that the controller carries out a set of activities and decides on a large number of routes and this is done within a short cycle of quickly performed acts. Flights move at between 1000 and $1600 \mathrm{~km}$ an hour, which means between three and four kilometers a second. Although the speed at which they move does not correspond to the same speed on the ground, it is experienced in the same logic of the displacement speed. Each controller is responsible for six flights simultaneously and at peak times, corresponding to the period between 6 a.m. and 9:30 a.m. and between 6 p.m. and 9 p.m. they also experience more intense traffic, when each one becomes responsible for up to 12 flights. In some cases a controller has as many as 20 flights simultaneously under their guidance.

As the support system data are transmitted at the speed the flights move, when the number of simultaneous flights increases the controller needs to be able to cope with this speed. This is why the activities are developed under pressure from the chronometer. It is necessary to be able to accompany the data that are transmitted as well as the volume of data corresponding to each flight. The data alter every three to four seconds. This demands that the controller rapidly visualizes the data to identify and memorize them. Besides this, they need to be able to cope with the different types of equipment involved in each of these flights, which have differing capacities and are flying at different speeds. This requires knowledge of the capacity of each one of these pieces of equipment and the possibilities of each one. Each airline company also adapts the equipment within their service models, even when they are operated under established rules.

The icons that represent flights in movement are numbers and letters, which are also differentiated by colors. Based on studies, such as those by Murch (1984) and Handbury \& Serra (2002), identifying colors requires as much cognitive effort as it does the physical force of the eye system, notably when the work is carried out in a digital environment, like the screen on a monitor. The colors are also differentiated by hue, intensity and shade, but hue is what distinguishes the color, as Dondis (1997) stated and the dimension of the color is given by the intensity, while shade is the value of its luminescence. So muscles move the lens to visualize the image of the desired object by way of the retina. To cope with greater or lesser amounts of light and reddish or blue colors, the lens changes to become more or less convex. So the eye system exerts physical force to cope with the change in colors, like the cognitive effort to identify and process their meaning within this context. For these reasons, Handbury \& Serra (2002) recommend avoiding intense colors, blinking signs and a dark monitor background that demand more of the eye system and increase eye fatigue. It was precisely these three items that were found to be present on the monitors of the air traffic controllers when the field survey was carried out.

The situations experienced in flight control show that the traffic controller is aware of the need to dominate the sector's traffic data. It also noted that each of them feels responsible for passenger safety in flight. They are concerned with always bearing in mind aviation rules and the weather information of the region and adjoining regions that is updated all the time in order to check the take-off and landing conditions at the airports they control. Weather changes have an influence on safety conditions and attention. Risk situations are avoided. Even so, controllers know that unpredictable and unexpected conditions occur all the time, even when they take all precautionary measures to ensure greater control. Because this is unpredictable and unexpected content, part of the work is unplanned and so is not considered beforehand. 


\subsection{Organization vs. Content}

Some aspects of the work content of the controller result from the organization and management of the process. Four of the aspects of this organization can be mentioned:

a. the composition of the teams and their working hours. In the control room in São Paulo, for example, the number of flights for each sector increases because of insufficient staff numbers. There are five teams, comprising fourteen controllers in each, who are spread across the day's three shifts, in addition to the teams that are used for covering vacations and rest days. There is a certain idea that working days, breaks and rest days are managed by the teams. However, what might appear like a certain notion of self-management of their working hours masks the responsibility that is attributed to them for ensuring teams are complete for all three shifts, 24 hours a day. What is implicit in the shift allocation decision is that if there are not enough people to complete the day's teams, many people feel obliged to double up their working day.

The justification for the lack of people is that staff numbers were not filled and there is now no possibility of hiring new people. This is a management accounting issue, however. In the control room in Rio de Janeiro, for example, the permanent staff contingent is 80 controllers, with 50 controllers in the control tower at Galeão Airport. But according to one of the supervisors, of the 80 controllers only 46 are available for shift work allocation. This represents almost half the staff. Of the 34 not available for nrormal control duties, some are on leave from the function, or have been sent to look after emergency situation, like systems maintenance and administrative services. Some had been invited to carry out investigations, while some of the controllers were on sick leave. There were also nine on vacation. The 46 are distributed across the 6 teams, with at least 8 controllers in each one. In each team there are two interns being trained and they need to be monitored, which is mainly done by the most experienced controllers.

b. a deficiency in the organization, which «is left up to the controllers » to sort out. There are failures and problems with the infrastructure in the airports, as is the case with São Paulo and Rio de Janeiro, with a large amount of air traffic. Functioning dimensions and conditions are disassociated from the increase in the number of landing and take-off operations and the circulation of passengers. As a result, the amount of time that flights need to be controlled increases, with an increase in the number of flights for each controller and greater time under their responsibility for vigilance and guidance, when flights are en route to the airport. Visibility problems are also frequent at these airports, above all in certain periods in the winter when there is dense fog, when it rains a lot and there are storms.

c. the fragility of the support system, given the complex activity. Breakdowns in the systems, which occur frequently, leave the controller « in the lurch », without any information. As the controllers recall it, « the system fails », it blocks, stops or blacks out, which is incompatible with the level of responsibility they have over flight safety. In these cases controller resort to the old control strategies that they used when there were no support systems for visualizing the data. However, as the controllers point out, this was used when the amount of air traffic was something other than it is now.

d. slow decision making when it comes to solving the defects that affect the functioning of the support systems. There is always the expectation that the solution for these failures and defects will be quick. This slowness assumes another dimension, since it relates to decisions that are not within the competence of the control room and require the action of other sectors, which have another time for doing things, both with regard to decisions about purchasing or exchanging parts or fixing the equipment. There is stress associated with this dichotomy between the pace at which controllers work and the demands to which they are submitted, given the speed of the systems and the amount of flight traffic, which is very different from the responses of the organization.

\section{Density, Effort and Collective Creation}

Air traffic control is an activity that allows for no mistakes. Decisions need to be taken within a precise timescale. As a result, the acts require accurate timing and correct information and this has to occur within the operation of the communication systems. Air traffic controllers need, above all, to make all the communication systems function. They are aware that they need to rely on visual data, which is transmitted by an information system. However, there are a considerable number of failures in each working day; failures in the way the equipment functions or even in data transmission systems are very frequent and increase at times when there are meteorological alterations, like rainfall, storms, fog, wind, etc. Furthermore, there are various other types of system breakdown, like a power outages, as we saw during the observation periods.

The daily experience of these controllers shows that they cannot always rely on this information and these communication systems, and this is a complex task. This is because it requires them to " get round the systems » in order to avoid blockages in the control system. This «getting round means anticipating the failures, testing different ways of obtaining data and relying on their knowledge and experience. When these operations are successful this is shared with their colleagues and tested by various people, and when it is effective it is adopted by everybody. 
However, the complex situations that appear are unpredictable. There are situations considered simple that arise from failures in the airport infrastructure or the air transport system itself. Flight delays, for example, affect the programming schedule both of take-offs and the landing of other flights. As a result they cause accumulative alterations in flight schedules. There are delays because of a lack of staff for loading and unloading baggage, for maintenance procedures and for refueling. But there are complex situations too, as is the case with a breakdown in the systems or power outages at peak periods or when it is raining. There are also flight incidents and accidents. In all these situations it is the flight controller who seeks out alternative solutions.

How can this learning and knowledge process be analyzed?

\subsection{Density and Effort}

Understanding the work of the air traffic controller includes also analyzing the process that links the tasks and that is not restricted to carrying out the tasks themselves. In this activity there is a cognitive process linked to language. Based on studies by Vygostky (1962) and Luria (1973, 1993 and 1996), we can say that there is a cognitive effort in this processing, notably when dealing with those traffic control functions in which data are fundamental instruments in the control decision process. Controllers work with data and their understanding of a piece of information cannot be wrong. In the same way, a demand from the pilot over the radio needs to be well understood. Attention is required for hearing and understanding the demand over the radio and for understanding the data that appear by way of images on the monitors. This is why attention is multiple. It is just as necessary for correctly identifying the data as it is for hearing, seeing and preparing information. These actions of seeing and hearing are essential. They include the functions of data treatment, which need above all vision. Sight needs to get accustomed to working in twilight with the monitors, for example, when the cells of the retina receive images in the form of luminous data. These data are transmitted to the brain by way of a physical-chemical mechanism, cone-like cells that are concentrated in the central part of the retina and used for seeing and recognizing colors.

In this activity the act of seeing is not a question of just looking, but of seeing well, seeing in order to be able read the data correctly. This means looking, seeing and understanding the data. These are visualized data that come from the support system of the monitor screens and that can be presented to the controller by way of a volume of information. These are air traffic data, like the movement of aircraft on the runways that is transmitted by the control systems of the control tower. They are also data of the planned time schedule and data about what is being done. They are also data of flight movements in the air space. The data are picked up by the radar, treated and transmitted by the support system. But it is up to the controller to identify those data that are most important, select them and prepare them.

\subsection{Guidance structure and knowledge network}

Studies that Sacks (1995) did with blind people can be important for understanding that the act of seeing in itself is not sufficient. The author shows, for example, cases in which it is necessary to see using the eyes, sight. But the world as we see it is not a given, but is constructed from experience, in a process of continuous and cumulative construction. It is necessary to identify and classify it in a never-ending process of visual memory that produces a network of representations and recognitions. The visual memory is an instrument that serves as support for visual perception, which allows us to perceive the world as we see it in a coherent way. The sensation of this coherence becomes a perception relative to visual behavior. Looking requires the construction of a framework, a guidance structure that is developed by way of the learning of space and time, of image and sound and by simultaneous visual perception. These data are recognized and reconstructed by treatment activities that are carried out by the brain, which comes from a capacity for analysis, synthesis and hierarchization. The sight captures the data that are treated to transform them into information in its multiple paths and that is transported under different aspects by the visual cortex, as Meyer (2002) analyzed it.

In this sense, we resort constantly to this guidance structure for looking at and understanding what is seen and for producing new representations and associations. These are neural connections using the visual memory, which is why we can construct on this structure what we might call a knowledge network. The use of this guidance structure and knowledge networks can be also compared with what Fayol (1992) called situation models, activities of the visual cortex that are being continuously transformed. In this sense an object we see must be recognized by the representation activity, by the memory and by the construction of an integrated representation model, by way of the interaction of the identification, data treatment and preparation of information on the existing knowledge networks.

\subsection{Understanding sound}

These processing activities, known as cognitive treatment, are carried out in environments with different noise levels. As the need to see also applies to the act of understanding, people need to listen well and understand well. That is why it can be analyzed as a learning process that is carried out by the simultaneous perception of image and sound and with the construction of sound representations in time and space. The act of hearing is developed on this guidance structure with 
the help of experience and in a never ending way, with each one of the sounds having its own meaning. This act of understanding sound demands the identification and processing of data for preparing the information so that people can understand what is being demanded of them and prepare solutions and act.

In the case of the control room in São Paulo, noise is a problem. Among the issues present in the control room is that of sensitivity to sound, notably after a period of two or three hours' work. Taking into account the problem of the tiredness to which the controllers are exposed, an assessment was carried out of the level of sound pollution. Noise levels were measured at different times of the day and night and on different days of the week and month. The result showed that noise was within the $75 \mathrm{~dB}$ (A) tolerance limit established by legislation. However the fatigue discourse of traffic controllers required an analysis of the noise they experience.

By way of audiology studies, like those by Boothroyd (1986) and Russo \& Santos (1993), we find that listening to what pilots say, over and above any other noise, requires neurocognitive activity. Understanding pilot demands over the radio depends on auditory processing, which involves detecting the words said, sensation, discrimination, localization, recognition, understanding, attention and memory. This requires that the controller perceives and interprets the sound models of what the pilot says and prepares a linguistic analysis of this demand.

The studies of Ptacek \& Pinheiro (1971) corroborate the above statements and we can say that in order for there to be accurate communication with the pilot these auditory processing movements are prepared by the hearing system and that it is not just physical, but above all neurocognitive. A demand is made of the hearing memory that absorbs the words of the pilot and stores the information. This information needs to be ordered in time, because processing it requires auditory perception of the temporal sequences and patterns of sounds for acquiring and understanding the conceptual or symbolic components of the language and the acoustic properties of the pilot's speech from the duration, frequency and intensity.

Sound in this control space is not, therefore, a simple noise that needs to be analyzed within this context. Exposure to constant and intermittent noise has an effect on the organism and on work performance. This exposure to noise requires a cognitive effort that, with the changes in mood and the sensation of fatigue that are apparent afet juste on and half hous of work at same pace, is effective to the extent that it produce disorders.

Sound, therefore, forms part of this content of the work process, over and above simple communication or noise. It is codified communication. The word that comes from a sound is an enunciation, with information, or a fact that is introduced in a system of relationships in a semantic field. Based on studies by Luria $(1982 ; 1986)$ we see that in this communication process work needs to be done for deciphering the system of sounds, which is not just listening. This process is constituted in stages, as the perception of the system of sounds, and by a system of verbal codes; deciphering or decodifying these codes and understanding the general meaning of the information.

To do their work, air traffic controllers need to be alert to the calls from the pilot over the radio and to telephone calls. The ear captures the sounds and then selects those that are a priority and those that are not. There is no selective listening, a priori. In this listening all the sounds in the room are intercepted, which is an experience of permanent listening. In these cases it is not the auditory apparatus that is overloaded, but the cognitive system. So it is not the volume of the sound, which is considered tolerable in general measurement, or the reference value of the standard tolerance of the sound pressure level that the organism can support, but the large volume of data that the ear sends from the sounds it hears to the cognitive system that needs to process it and that is translated as being a large volume of information. The ear collects and retransmits the signals as codified sounds, as words that represent data.

Among the situations experienced by the controllers there are two main ones to be analyzed. In the first situation the number of flights controlled that is considered acceptable is between one and four and they manage to accompany the time schedule program of the flights. This programming appears on the monitor of each controller, divided by sector. Flights can be visualized by way of icons that appear on the monitor, indicated by a code, two letters and a number. This code indicates the flight number and its altitude. The controller is vigilant and accompanies each of the flights and calls the pilot to provide guidance on the route. In the second situation each controller is faced with a large number of flights, between six and twelve. The controller is unable to control everything and monitor the program as is necessary. But this number of flights can reach twenty, as occurred on various occasions. At this moment it is always the pilot who calls first to inform his position and ask for guidance.

In these situations, the traffic controller pays attention to all the information coming from the pilot via radio communication. He compares it with the data he can see on his monitor and also in the programmed sequence. The controller checks all the data, assesses it and certifies it. This assessment means analyzing the data that arrive, the various pieces of information he has and comparing it with the existing data. He then checks the route possibilities in the air space represented on the monitor, the distribution of flights in the space and the flights subsequently programmed. For this he needs to assess the time necessary for a flight to pass through a particular air space by way of a 
calculation he does of seconds and minutes. He also confirms the calculation to ensure the position to be allocated to a flight on a specific route.

This whole assessment process is carried out from the data presented on the monitor. The controller identifies them and those relative to the routes and distribution of flights in the space, by analyzing them with the flights that are programmed subsequently for that route. The controller does not attribute a route to a pilot until they are certain and dominate all these facts. They decide on the route and transmit it within the space available when they are certain of the seconds and minutes available for this flight on this particular route. In this second situation the controller feels they are not always in control of the whole situation. In fact, the norms and rules are set aside and people « roll up their sleeves and pray to God». This is when people chase after things, as controllers always say. The figurative term, also created in the everyday speech of the control tower, of «chasing after things », means carrying out activities at a fast pace, in fractions of a second, seeking to cope with « racing against the clock»; and all this effort is to avoid greater problems.

\subsection{Knowledge and Creation}

We also found unforeseen and uncertain situations in this work of traffic controllers, which demand redoubled attention to control collision risks, accidents, on a permanent basis. In this process the cognitive activities are engaged and permanently functioning in order to solve problems and incorporate the construction of the mental representation of situations into the new data that must be composed for preparing information. This action also requires analytical anticipation activities to control situations that may conflict. To do so the controller needs to mentally assess a situation in a subsequent scenario at a near future moment in time. And he is prepared for this. When this occurs the action needs to be correct, prompt and is usually one-off. The memory containing registered data is used for this assessment and among these data are those shown on the monitor. These data alter every four seconds; the time schedule program and the data that are printed on the strip change every four seconds.

When an unforeseen situation occurs, the controller has recourse to his memory to review similar situations he has experienced before and the strategies that are established for it. He also discusses it with his colleagues to check out solutions and alternatives. Every time conflicting situations occur with routes and flights the controller discusses them with his colleagues and his bosses. In fact, different or unforeseen decisions are always discussed to ensure the best alternatives. These unforeseen situations, which are not established in the rules, are frequent. The team develops strategies for facing up to the different problems that appear. This is why they put into practice work that is elaborated as creation to respond simultaneously to the demands.

Based on studies by Vigotsky (1986) and Luria (1986), people are capable of creating images of numbers, sounds and colors using their experience. But the social environment is considered to be an important factor in the development of the complexity of the mental activity. These images may be graphic, optical, perceptual, mental or verbal. Mental images can be developed by the memory and by ideas. Interests, needs and emotions are part of the motivation that stimulates thinking. In this work there is image content and representations, as well as textual or symbolic spoken words like communication signs. But these spoken words, as text or signs, are part of the long time work experience that is shared between the controllers. Perceptual images may be absorbed by the senses as well by visualisaton of the appearance. But these images have a meaning that is also shared. They are images in movement that are transformed into a mental image or idea.

However, a positive perception of the meaning of the activity can be noted. This meaning of the importance of the activity exceeds the notion of work with tasks to perform. The work of air traffic control is much more than a task to be performed. It becomes relevant as results, based on both what the controller attributes to it and also from the perception of the importance that is attributed to this activity. This perception of the value that is attributed to this activity, both by the reference group and by society as a whole, starts to play an important role in the identity imaginary. This was understood by Castoriadis (1975) as an identity reflection that contributes to the affirmation of social and professional identity as such.

Along this same line of understanding the experience of São Paulo subway workers was analyzed (ITANI, 1997). Within the context of the subway being introduced between 1970 and 1980, the success of the undertaking at that moment in time, with its innovative and automated technology within a social and industrial fabric that was still developing, relied on the effective action of the workers. This was much more than the result of the effectiveness of management strategies; this was an effort, a super-effort, by the subway workers. It's can also be considered to be an occupation of political action spaces by way of the possibilities present at that time. It was also understood as an effort at insertion by a group of workers into a new world of codes and systems. It was an effort to create a new social and professional condition, that of "subway laborer". Then, more than an intended participation submitted to control it can be understand by the worker organization within the production process.

Referring to the studies on the question of relevance of Sperber \& Wilson $(1986 ; 1995)$ communication is effective 
when there is a reciprocal assessment of a particular subject between the speakers, which is shared cognitively. By this theory of relevance the construction of a collective idea can only be promoted when a group previously assesses the relevance of what needs to be done. This communication does not necessarily have to be by way of words. But it is assumed to be textuality, in other words, the communication is constructed by the memory and cognition. From these studies by Luria (1986), Vygotsky (1986), and Sperber \& Wilson (1995) we can say that there is collective creation that results from a cognitive effort arising from the stimulus that this activity represents, as well as from the result or the product that is presented as resulting from this work.

However, this involvement may also have its setbacks. Involvement may be highly positive and healthy and it may also be stressful. In some cases there is a lot of involvement and the worker requires perfection in carrying out the task and in the result and they are not always able to mobilize the organizational structure in which the activity takes place to the same extent, so cases of stress are common.

\section{Final Considerations}

The work of air traffic controllers is an experience that cannot accept misunderstanding. Air traffic controllers never stop or vacillate in their activity. They are always ready. They do not feel at ease asking for information to be repeated that they did not hear clearly, or that they may not have fully understood. They need to decide at the moment they are called. These are activities that demand the cognitive treatment of a set of sounds, numbers and letters that represent the words of the pilots, the flights and the routes in the air space that appear on the screen of their monitor. Controllers do not see objects, but work with the sound and visual representation of a knowledge network, which requires an effort by the neurocognitive system.

This work cannot be understood from the activities they do in the function that is established for them, but in the development of the process, in the ways in which they seek means to cope with the responsibilities they assume within their functions. It is not only a problem of the pace of work, but its density, which requires concentrated efforts on the part of the worker in order to complete the work. This density is always submerged by a work capacity of the workers, but also involves the creation process of a set of strategies that are developed and put in place by the controller in this activity so he can «sort it out himself ». This is the creation of knowledge that is diluted in a vague concept of qualification. In order to carry out the activity, guidance schemes are created and developed. This is work capacity in action, which demands to be analyzed from another perspective; one that is interwoven with various meanings, since it is constructed in the daily routine of the work situation. We find strategies for defending themselves from the super-effort, above all to protect themselves from risks and avoid the health damage to which they are exposed.

Even when we consider that this work is under military control and subject to strict rules from the military perspective, we found that these workers develop knowledge and create strategies in order to make the systems they operate work. This control would not function without the structures that are created and developed in order to carry out the traffic control function better. In this process there is a mobilization of effort and capacity associated with the knowledge that is developed. The activity is appropriated to make it professional. From being someone who accomplishes tasks, the controller develops in this experience to make this work an active process and they are the subject of their own knowledge and capacity. So, it is constituted as the result of the knowledge that is constructed within this work situation and it is, therefore, the result of a collective creation.

It is also an experience of work with a risk content. The risks are accidents and incidents, which are impressive significant, given the degree of unpredictability and uncertainty of the automated systems. It is also experiencing the number of uncertainties and unforeseen situations that come from different points, from the systems, the equipment, the flight teams, the weather and problems arising with the airport infrastructure. Associated with these are the difficulties arising from the incongruences of air traffic organization systems, notably as far as concerns the infrastructure and the maintenance programs, as well as the functioning of on board equipment and systems and systems on the ground. These are facts that the controller faces as common in their daily routine. In short, they are confronted also by other risks, above all those arising from the forms of organization and management policies as they are established in this workspace. As this is work in which the chronometer is implacable it is also professionalism put into practice to cope with the degree of responsibility attributed for passenger safety during the lengthy time it is being monitored.

In this collective creation we see that a group effort is really made in the search for common purposes, which are taken as their own, because controllers have developed a common language that is used by the group with a common perspective of achieving the objectives of the activity. We also find appropriation of the work as part of a work process that is verbalized, as a product obtained by the group and that is effective and recognized as such. This work is constructed in a dynamic process and the perspective of the experience as a way of analyzing this process helps bring to the surface what cannot always be apprehended.

The rules of the code of ethics were followed. The reports were discussed with SINPROVOO (Protection Controller and 
Flight Controller Trade Unions).

\section{Acknowledgements}

Our thanks to all air traffic controllers, especially to Ruy Ciarlini and José Carlos Botelho of Sinprovoo, to FAPESP and CNPq for the funds for carrying out this study in aviation. Our thanks to Eda Muller, Paulo Sergio Silva, Rita Araujo and José Carlos do Carmo of the Cerest Centro de Referência em Saúde do Trabalhador, that they working between 1998 and 2000 in APP-São Paulo. Our thanks to Robert Dirham for help with revision.

\section{References}

Agência Nacional da Aviação Civil ANAC. (2013). Anuário do transporte aéreo. Brasilia: ANAC.

Boothroyd, A. (1986). The sense of hearing. In: A. Boothroyd (ed.), Speech, Acoustic and Perception Disorders. Austin: Pro-Ed Studies in Communicative Disorders.

Castoriadis, C. (1950). L'expérience du mouvement ouvrier, 2, Paris, UGE/10/18. (reimprinted in 1974 UGE/10/18).

Castoriadis, C. (1975). L'institution imaginaire de la société. Paris: Seuil.

Dondis, D. A. (1997). Sintaxe da Linguagem Visual. São Paulo: Martins Fontes.

Fassin, D. (1996). L'espace politique de la santé. Paris: PUF.

Fayol, M. (1992). Compreendre ce qu'on lit: de l'automatisme au contrôle, in M. Fayol et al. (Eds.) Psychologie cognitive de la lecture. Paris: PUF.

Habermas, J. (1984). La technique et la science comme "idéologie". Paris: Denoël.

Hanbury, A., \& Serra, J. (2002). 3D-polar coordinate colour representation suitable for image analysis. Institute of Computer Aided Automation. Pattern Recognition and Image Processing Group. Technical report PRIP-TR-077, Wien.

Itani, A. (1997). Subterrâneos do trabalho. São Paulo, Hucitec/Fapesp.

Itani, A. (1998). Trabalho e saúde na aviação. São Paulo:Hucitec/Fapesp.

Itani, A. (2009). Com a cabeça no ar. Trabalho no tráfego aéreo. São Paulo: Fapesp/Hucitec.

Luria, A. R. (1973). The working brain. London: Penguin.

Luria, A. R. (1982). Language and cognition. New York: John Wiley.

Luria, A. R. (1986). Pensamento e linguagem. Porto Alegre: Artmed.

Meyer, P. (1997). L'oeil et le cerveau. Paris: Odile Jacob.

Mitchell, W.J.T. (1986). Iconology: Image, Text, Ideology. Chicago: Chicago University Press.

Moreira, S. B., \& Vidal, M. C. (1999). Relatórios de pesquisas ergonômicas realizadas no Controle de Tráfego Aéreo do Rio de Janeiro (APP/RJ). Rio de Janeiro: APP/RJ. Technical Report.

Motter, A. A. (2007). Análise da carga de trabalho em sistemas complexos: Gestão da variabilidade e imprevisibilidade nas atividades do controlador de tráfego aéreo. (Unpublished doctoral thesis). Universidade Federal de Santa Catarina, Florianópolis, Brazil.

Murch, S. (1984). IEEE Computer Graphics and Applications, 4(11).

Panofsky, E. (1939). Studies in Iconology. Oxford: Oxford University Press.

Ptacek, P.H., \& Pinheiro, M. (1971). Pattern reversal in auditory perception. Journal of Acoustical Society of America, 49(2), 3-8. http://dx.doi.org/10.1121/1.1912377.

Russo, I. C. P., \& Santos, T. M. M. (1993). A prática da audiologia clinica. São Paulo: Cortez.

Sacks, O. (1995). An anthropologist on Mars. New York, NY: A. A. Knopf.

Sperber, D., \& Wilson, D. (1986). Relevance: communication and cognition. Oxford: Blackwell.

Sperber, D., \& Wilson, D. (2002). Pragmatics, modularity and mind-reading. Mind \& Language, 17(1), 3- 23. Retrieved from HAL Id: ijn 00000002 http://jeannicod.ccsd.cnrs.fr/ijn 00000002.

Tragtemberg. M. (1980). Administração, poder e ideologia. São Paulo: Moraes.

Vygostky, L. S. (1987). Pensamento e linguagem. São Paulo: Martins Fontes.

\section{(cc) EY}

This work is licensed under a Creative Commons Attribution 3.0 License. 